ISSN 00156043

\title{
EDITORIAL
}

\section{La cooperación con el desarrollo en tiempos de crisis. El caso español'}

\section{Consejo de Redacción}

Palabras clave: desarrollo, cooperación con el desarrollo, "nueva arquitectura", objetivos de desarrollo del milenio, plan director de la cooperación, eficacia de la ayuda, calidad de la ayuda, empoderamiento, desarrollo íntegro y solidario.

Key words: development, cooperation for development, "new architecture", Millenium development objectives, guideline for cooperation, efficacy of aid, aid quality, empowerment, broadening of capacities, integral and humane development.

Mots-clés: développement, coopération pour le développement, "nouvelle architecture", objectifs de développement du millénaire, plan directeur de la coopération, efficacité de l'aide, qualité de l'aide, développement des capacités, développement intégral et solidaire.

Puede sorprender a nuestros lectores que abordemos la cooperación al desarrollo cuando estamos sintiendo los efectos alarmantes de una crisis de envergadura como la que atravesamos. Joseph E. Stiglitz (economista jefe y vicepresidente senior del Banco Mundial en el periodo 1997-2000 y premio Nobel de Economía 2001) ha llegado a decir de ella que "la caída de Wall Street es para el fundamentalismo de mercado lo que fue la caída del muro de Berlín para el comunismo". ¿Es ésta la coyuntura mejor para reflexionar sobre nuestra cooperación con los países en desarrollo? ¿ No hay urgencias más prioritarias?

\footnotetext{
${ }^{1}$ Fecha de cierre del editorial: 23 de febrero de 2009.
} 
Para justificar el tema de este editorial y su oportunidad recordamos que, junto a la crisis financiera y económica que padecemos, no deberíamos olvidar los compromisos del gobierno español de avanzar decididamente con un aumento de la cuantía de los fondos destinados a la ayuda y con una renovación de la estrategia a seguir para su uso. Hay una relación tan estrecha como peligrosa entre ambas cosas. En palabras de un reciente informe de INTERMÓN-OXFAM:

Las crisis alimentaria, climática, financiera y económica están teniendo consecuencias dramáticas para millones de personas que viven en los países del Sur. Sin embargo, el conjunto de países donantes ha disminuido su ayuda al desarrollo en los dos últimos años. En este contexto, España ha sido el país que más ha incrementado la cooperación con los países en desarrollo, con el objetivo de cumplir con la meta marcada de alcanzar el 0,7\% prometido para finales de la legislatura, pero con grandes retos y contradicciones ${ }^{2}$.

Para nosotros la crisis no es una razón para aparcar temporalmente la cooperación para el desarrollo, sino todo lo contrario. Precisamente porque es más fácil que los poderes públicos la olviden para atender otras urgencias y porque es probable que la sensibilidad social hacia esas políticas disminuya por la presión de lo que ahora es nuestro "problema número uno", hemos creído más necesario dedicar estas páginas a un tema que siempre ha sido objeto de nuestra preocupación y ahora lo es por nuevos motivos. En el fondo nos inquietaría que sólo fuésemos solidarios en tiempos de bonanza y que olvidáramos que nuestra crisis de ahora fue precedida por una de consecuencias más dramáticas para una parte importante de la humanidad, la crisis alimentaria, que se tradujo en un aumento considerable del hambre en el mundo.

Así lo reconocía también un reciente documento del Consejo Pontificio Justicia y Paz:

La preocupación por la emergencia financiera que se ha originado en los mercados maduros efectivamente puede ofuscar la necesidad de financiar el desarrollo. Es razonable pensar que la ayuda pública al desarrollo, que procede de asignaciones del

\footnotetext{
2 InTERMÓN OXfaM (2008) Informe sobre la realidad de la ayuda 2008-2009 (dirigido por Jaime Atienza). Nuestra revista ha reflexionado con anterioridad sobre la crisis financiera: cf. CONSEJO DE REDACCIÓN (2007) "Claves para comprender la crisis financiera internacional": Revista de Fomento Social 62 (2007) 515-535; más recientemente la revista también se ha ocupado de la crisis de los precios de los alimentos: cf. CONSEJO DE REDACCIÓN (2008) "El hambre, ìtsunami silencioso?": Revista de Fomento Social 63 (2008) 383-409. Otros dos buenos análisis: K. CAsCante Hernández - A. Sánchez Dízz (eds.) (2008) La crisis mundial de alimentos: alternativas para la toma de decisiones, Madrid, Fundación Alternativas, Madrid; F. MousSEAU - M. BAllEY (2009) Mil millones de personas hambrientas Los gobiernos y las agencias de ayuda deben hacer frente al reto, Informe de Oxfam Internacional ${ }^{\circ}$ 127, INTERMÓN-OXFAM, 39 pp.
} 
presupuesto que cada país establece de año en año, sufrirá a causa de los ingentes recursos públicos necesarios para tapar la emergencia de la crisis financiera. $Y$ esto es un mal, indiscutiblemente. Una financiación al desarrollo adecuada requiere un horizonte de largo plazo: es necesario que los recursos afluyan de modo previsible, en condiciones favorables, para financiar obras que quizás requieren mucho tiempo antes de producir beneficios a la población local ${ }^{3}$.

En estas circunstancias menos propicias, nuestro objetivo no es otro sino el de proponer algunas consideraciones acerca de la actual política española de cooperación al desarrollo, en el contexto más global de la ayuda internacional. Para eso comenzaremos describiendo los elementos fundamentales de lo que ha dado en llamarse "la nueva arquitectura" del sistema internacional de ayuda al desarrollo, marcado por los Objetivos de desarrollo del milenio (ODM) y los nuevos paradigmas relativos a la eficacia y a la financiación de la misma ayuda. A continuación, haremos un breve balance de la evolución reciente de la cooperación española para el desarrollo tanto en cantidad como en calidad, haciendo una breve referencia al Tercer Plan Director de la Cooperación Española que ha sido aprobado por el Consejo de Ministros del 13 de febrero de 2009 y remitido al Congreso de los Diputados. Concluiremos, siguiendo nuestra costumbre, con algunas reflexiones éticas de fondo relacionadas con los valores en juego en esta coyuntura mundial.

\section{El contexto internacional: hacia una "nueva arquitectura" de la ayuda}

No es tarea fácil resumir en pocas páginas las principales tendencias del sistema internacional de ayuda al desarrollo. Aun a riesgo de simplificar y de esquematizar, nos ceñiremos a algunos aspectos más destacables que configuran el panorama actual.

\footnotetext{
${ }^{3}$ Consejo PontiFICIO Justicia y PAZ, Nota de la Santa Sede Financiación y desarrollo, sobre la financiación del desarrollo en vísperas de la Conferencia de Doha, 18-XI-2008, 4. Consulta en www.vatican.va/ roman_curia/pontifical_councils/justpeace/documents. Esta nota fue publicada por el citado organismo de la Santa Sede con ocasión de la conferencia promovida por la Asamblea General de las Naciones Unidas en Doha sobre Financiación del Desarrollo, a la que nos referimos más adelante. Es un texto donde se critica con claridad el actual orden económico internacional y donde se proponen medidas interesantes en pro del bien común de la humanidad y de los empobrecidos de nuestro mundo.
} 


\section{I.I. Un horizonte compartido: los Objetivos de Desarrollo del Milenio. Luces y sombras}

Es un hecho ya muy conocido que, en septiembre de 2000, en la Cumbre del Milenio de las Naciones Unidas, los dirigentes mundiales acordaron una serie de medidas para combatir la pobreza, el hambre, las enfermedades, el analfabetismo, la degradación del medio ambiente y la discriminación contra la mujer, y para crear una asociación mundial para el desarrollo.

Este pacto mundial, conocido como los Objetivos de Desarrollo del Milenio (ODM), fue acordado por todos los países miembros de las Naciones Unidas, por lo que significa una buena expresión de la solidaridad mundial (Cuadro 1). En la Declaración de la Cumbre del Milenio (2000) se esbozó además un plan, igualmente acordado por consenso, sobre la forma de aplicar los acuerdos: en ella se expresaba el compromiso de prestar más atención a los derechos humanos, a la buena gestión de los asuntos públicos y a la democracia, así como a la prevención de los conflictos y a la consolidación de la paz. A partir de entonces todas las agendas del desarrollo incluyen los objetivos del milenio como una referencia obligada en sus planes de acción de lucha contra la pobreza. Existe una estrecha relación entre los diferentes objetivos: concretamente la lucha contra el hambre tiene un carácter estratégico, ya que, sin avanzar en ella, es difícil progresar en otros; esta dependencia es también evidente entre el crecimiento, la reducción de la pobreza y el desarrollo sostenible, de forma que las políticas deben enlazar bien estos aspectos para cumplir esos objetivos.

\section{CUADRO 1. Los Objetivos de Desarrollo del Milenio}

- Reducir a la mitad, entre 1990 y 2015, la proporción de personas que viven en la pobreza extrema (menos de 1 dólar diario).

- Matricular a todos los niños en la escuela primaria para 2015.

- Avanzar hacia la igualdad entre sexos y dar poder a la mujer, eliminando las disparidades entre sexos en la enseñanza primaria y secundaria para 2015.

- Reducir la tasa de mortalidad infantil en dos terceras partes entre 1990 y 2015.

- Reducir la mortalidad materna en tres cuartas partes entre 1990 y 2015. 
- Combatir el SIDA, el paludismo y otras enfermedades.

- Garantizar la sostenibilidad del medio ambiente: poner en práctica para 2005 estrategias nacionales de desarrollo sostenible a fin de revertir para 2015 la pérdida de recursos ecológicos.

- Fomentar una asociación mundial para el desarrollo.

Es destacable que en los ODM no se establezcan sólo objetivos, sino metas mensurables y plazos para su cumplimiento. Es más, puede decirse que la agenda del desarrollo en general, y la arquitectura de la ayuda en particular, han quedado indisolublemente ligadas a esta batería de objetivos, por muy moderados que nos puedan parecer. No hay plan, programa, estrategia o proyecto de desarrollo que no incluya entre sus finalidades el avance hacia la consecución de estos objetivos que se han transformado en una especie de mantra del mundo del desarrollo y de la cooperación.

Los datos disponibles sobre el grado de cumplimiento de los ODM muestran que los resultados son dispares. Según Naciones Unidas ${ }^{4}$, de cara al horizonte 2015 hay signos de esperanza, pero también una serie de metas pendientes casi imposibles de alcanzar (Cuadro 2).

\section{CUADRO 2. Los ODM: signos de esperanza y retos pendientes}

\section{Signos de esperanza: metas alcanzables}

- El objetivo general de reducir la pobreza absoluta a la mitad está al alcance en todo el mundo.

- En todas las regiones, excepto dos, la matrícula en la enseñanza primaria es por lo menos del $90 \%$.

- El índice de paridad de género en la educación primaria es $95 \%$ o superior en seis de las 10 regiones, incluidas las más pobladas.

- Las muertes causadas por el sarampión se redujeron y cerca del $80 \%$ de los

\footnotetext{
${ }^{4}$ Véase la última evaluación oficial actualizada: NACIONES UNIDAS (2008) Objetivos de desarrollo del milenio, Informe 2008, Nueva York, Naciones Unidas, 56 páginas.
} 
niños en los países en desarrollo reciben actualmente una vacuna contra el sarampión.

- La cantidad de muertes por SIDA se redujo de 2,2 millones en 2005 a 2 millones en 2007 y la cantidad de personas recientemente infectadas disminuyó.

- La prevención del paludismo se está expandiendo, con aumentos generalizados del uso de mosquiteros con insecticida.

- Se espera que la incidencia de la tuberculosis se detenga y comience a disminuir antes de 2015.

- Unos 1.600 millones de personas han obtenido acceso a agua potable desde 1990.

- El uso de sustancias que agotan la capa de ozono ha sido casi eliminado para reducir el calentamiento global.

- La proporción de los ingresos de exportaciones destinadas al servicio de la deuda externa se redujo notablemente.

- El sector privado aumentó la disponibilidad de medicamentos esenciales.

- La telefonía móvil creció rápidamente en el mundo en desarrollo.

\section{Retos pendientes}

- Es muy poco probable que se pueda lograr la meta de reducir a la mitad la proporción de personas del África subsahariana que vive con menos de un dólar por día.

- Aproximadamente la cuarta parte de la totalidad de los niños de países en desarrollo padecen desnutrición.

- De los 113 países que no alcanzaron la paridad de género en la matrícula de enseñanza primaria y secundaria para la meta de 2005, sólo 18 tienen alguna probabilidad de alcanzar el objetivo para el año 2015.

- Casi dos tercios de las mujeres empleadas en el mundo en desarrollo están en empleos vulnerables por cuenta propia o en una empresa familiar.

- En un tercio de los países en desarrollo, las mujeres representan menos del $10 \%$ de los parlamentarios.

- Más de 500.000 futuras madres de los países en desarrollo mueren anualmente en el parto o por complicaciones en el embarazo. 
- Aproximadamente 2.500 millones de personas, casi la mitad de la población del mundo en desarrollo, vive sin servicios de saneamiento mejorados.

- Más de un tercio de la creciente población urbana de los países en desarrollo vive en tugurios.

- Las emisiones de dióxido de carbono han seguido aumentando.

- Los gastos de asistencia extranjera de los países desarrollados se redujeron.

- Las negociaciones comerciales internacionales están muy atrasadas (estancamiento a finales de 2008 de las negociaciones de la llamada Ronda de Doha de la Organización Mundial del Comercio).

El avance está siendo desigual según grandes áreas y, desde luego, el recorrido seguido por África subsahariana no da pie para grandes esperanzas ${ }^{5}$. Una prueba de ello es el estallido de la crisis alimentaria de estos años.

Sin embargo, según INTERMÓN-OXFAM,

...el que está más lejos de cumplirse es el Objetivo 8, una Asociación Mundial para el Desarrollo. Mientras países pobres como Mozambique, Ruanda, Tanzania, Burkina Faso, Mali, Ghana, Kenia, Malawi o Bangladesh han demostrado que los avances en ODM son posibles, las brechas de ejecución y de cobertura provocadas por el incumplimiento de los países desarrollados continúan agrandando la brecha de las necesidades ${ }^{6}$.

Por último, dos consideraciones adicionales. En primer lugar, sea cual sea el grado de avance en la consecución de los objetivos acordados, lo primero que hay que destacar es que nos encontramos ante objetivos "de mínimos", una especie de "rebaja" (quizás inevitable en aras del consenso) de lo que debería ser un verdadero desarrollo humano concebido como "ampliación de capacidades", según

\footnotetext{
${ }^{5}$ Sobre las perspectivas de cumplimiento de los ODM en África y las acciones necesarias: Cfr. United Nations Secretary General (Chair) (2008) Achieving the Millennium Development Goals in Africa. Recommendations of the MDG Africa Steering Group, Nueva York, junio de 2008, 39 pp. Este grupo, coordinado por el Secretario General de Naciones Unidas, reúne a los responsables de las grandes instituciones internacionales de desarrollo: Banco Mundial, Fondo Monetario Internacional, Comisión Europea, OCDE, Banco Africano de Desarrollo, etc. Véase: www.mdgafrica.org.
}

${ }^{6}$ Cfr. INTERMÓN-OXFAM, l. c. 
la expresión utilizada por Amartya Sen ${ }^{7}$. Aunque haya que luchar por alcanzar estos objetivos, el desarrollo humano e inclusivo, es decir para todos, no puede conformarse con semejantes metas. En segundo lugar, y como ya indicábamos al principio, el desencadenamiento de las crisis, con el consiguiente riesgo de que todavía se deteriore más la situación en los países empobrecidos, no hace más que reforzar la necesidad de mantener el compromiso de alcanzar los ODM.

\section{I.2. Nuevos consensos sobre la eficacia de la ayuda: las Conferencias de París (2005) y Accra (2008)}

Hacia finales de la década de los años 1990 se produjo un fuerte cuestionamiento del valor y la eficacia de la Ayuda Oficial al Desarrollo (AOD): en efecto, tras tantos años de desembolso los resultados estaban lejos de ser los esperados. Esta presunta "fatiga de la ayuda" ○ "fatiga del donante" ${ }^{\prime 8}$ produjo una reacción importante en forma de estudios e investigaciones que trataban de valorar la eficacia de esta ayuda y las condiciones para que mejorara. El enfoque adoptado buscaba básicamente verificar la conexión entre ayuda y crecimiento económico y mostraba, además, cómo ese vínculo era más sólido cuando los países receptores contaban con buenas instituciones y buenas políticas. De esa convicción se ha seguido la puesta en marcha de criterios y mecanismos para seleccionar la asignación de ayuda a los países, una cuestión que está llamada a reavivarse en el contexto actual.

En marzo de 2005 tuvo lugar en París la reunión del llamado Foro de Alto Nivel, convocado por el Grupo de trabajo sobre la eficacia de la ayuda del Comité de ayuda al desarrollo (CAD) de la OCDE9. Si los ODM han sido el horizonte de la

\footnotetext{
7 De ahí nuestra reticencia a que se utilicen tan profusamente indicadores de pobreza y de hambre para formular políticas de desarrollo efectivas en los países en desarrollo y nuestra preferencia por conceptos como el desarrollo humano, desarrollo inclusivo o similares. Pasar de 1 a 2 dólares diarios, ¿resuelve el problema? Por otra parte, puede existir el peligro de que estos "acuerdos de mínimos" se conviertan en una forma de cubrir las apariencias y de tranquilizar las conciencias.
}

${ }^{8}$ En aquellos momentos, reflexionábamos sobre ello en nuestra revista: J. J. ROMERO RODRíGUEZ (1999) "La Cooperación al Desarrollo bajo el síndrome de la fatiga del donante": Revista de Fomento Social 54 (1999) 443-473. Se analizaba allí el conjunto de razones que explican esa "fatiga" (cfr. pp. 456-460): en particular, el convencimiento de que los mecanismos de ayuda resultaban inadecuados y de que las cosas se podrían hacer de otra manera. Véase también M. González MarTín (2006) "Gobernanza, desarrollo y ayuda internacional. Una revisión de los debates actuales": Revista de Fomento Social 61 (2006) 25-55.

${ }^{9}$ La bibliografía sobre la Declaración de París es interminable. Para lo que sigue nos basaremos funda- 
ayuda internacional al desarrollo, podríamos decir que la Declaración de París ha servido de hoja de ruta del objetivo 8, el que afectaba directamente a los países donantes, estableciendo cómo se conseguirá en la práctica fomentar una asociación mundial para el desarrollo.

La Declaración de París quiere orientar la acción internacional en cooperación al desarrollo en función de cuatro objetivos, que se enumeran en la exposición de motivos: $1^{\circ}$ ) aumentar la eficacia de la ayuda al desarrollo; $2^{\circ}$ ) adaptarla y aplicarla a las distintas situaciones de los países; $3^{\circ}$ ) especificar indicadores, calendarios y metas; $4^{\circ}$ ) supervisar y evaluar la ejecución. Establece además cinco principios "renovados", pues aunque no sean nuevos, son los actualmente subrayados, sobre los que apoyar el controvertido tema de la eficacia de la ayuda: por la importancia que tienen pasamos a hacer una descripción más detenida de ellos.

a) Apropiación. La Declaración de París la define como el ejercicio por parte de los países socios (receptores de la ayuda) de una autoridad efectiva sobre sus políticas y estrategias de desarrollo, de forma que sean ellos los que coordinen las acciones de la ayuda. El principal mecanismo para la apropiación es la elaboración de una Estrategia nacional de reducción de la pobreza (ERP), que incluya amplios procesos consultivos, cuidando especialmente la participación de la sociedad civil. La ERP debe poder traducirse en programas operativos priorizados y orientados hacia resultados, así como focalizados en el logro del cumplimiento de los ODM. Los donantes, por su parte, se comprometen a reforzar la capacidad nacional para realizar estas tareas.

b) Alineación. Por alineación debe entenderse el compromiso de que los donantes presten su ayuda considerando las estrategias, sistemas de gestión y procedimientos ya establecidos en los países socios, y no generen estructuras paralelas diseñadas para satisfacer usos propios de gestión poco pertinentes para los receptores. Con ello se pretende disminuir los costes de transacción y reforzar la capacidad del país receptor de gestionar la ayuda con mayor autonomía y apropiación. Es en este principio donde se aborda con más profundidad la forma de cooperar con los denominados "Estados frágiles", aquéllos con mayores dificultades para garantizar las condiciones de gestión eficaz de una ayuda menos "controlada" por los donantes. Los mayores retos para avanzar en este principio son el refuerzo de la capacidad de los países socios y la confianza que los donantes deben depositar en ellos, en detrimento de unos controles más afines a los propios sistemas de

mentalmente en el trabajo de J. M. LarRú Ramos (2005) “La declaración de París-2005: principios para una ayuda eficaz y aplicaciones para las ONGD": Revista de Fomento Social 60 (2005) 243-281. 
intervención de cuentas y gastos públicos. Numerosos donantes exigen sistemas de gestión propios y diferenciados, lo que supone una carga burocrática excesiva para el personal de los países en desarrollo.

c) Armonización. Este principio invita a los donantes a coordinarse entre sí para practicar una ayuda más predecible en sus cuantías, plurianual y de largo plazo, tratando de aprovechar las ventajas de cada donante y de evitar la dispersión de las acciones y las decisiones unilaterales y discrecionales de cada donante (que a menudo vacían de contenido las políticas públicas que el socio receptor quiere aplicar, para las que no dispone de recursos). La armonización pretende aumentar la transparencia y la eficacia, mediante la simplificación de procedimientos, los acuerdos comunes (financiación, evaluaciones medioambientales o ayuda no ligada), la información compartida (en especial los diagnósticos de países, realizados por los donantes), el fomento de los instrumentos de ayuda plurianuales y predecibles lapoyos presupuestarios macroeconómicos o sectoriales o ayuda programática sectorial de largo alcance), las "cooperaciones delegadas" (o "cooperación silenciosa", entendida como un convenio por el que uno o varios donantes solicitan a otro administrar sus fondos y asumir responsabilidades fiduciarias en su nombre) en especial, cuando un donante no cuente con presencia en un país socio. Muchos de los temas son comunes con la alineación a que nos hemos referido en el apartado (b), si bien la armonización enfatiza la coordinación de instrumentos y acciones entre los propios donantes.

d) Gestión orientada a resultados. Con este principio se pretende superar una forma de trabajo, limitada a plazos cortos y orientada simplemente a comprobar el cumplimiento de las actividades previstas y el logro de los resultados formulados. La evaluación por objetivos va mostrando que las actividades previstas en los proyectos y programas se ejecutan, pero que no suponen cambios sostenibles en el tiempo y que las comunidades beneficiarias siguen sumergidas en los círculos viciosos que causan su pobreza. La gestión orientada hacia los resultados obliga a cambiar muchos enfoques demasiado centrados en la propia cooperación -frecuentes en muchos agentes directos de la cooperación, incluidas ONGD- para pasar a poner toda la atención en el desarrollo. Lo importante no es la cooperación, lo importante es el desarrollo.

e) Mutua responsabilidad. El último principio, inicialmente ligado al anterior aunque con propia relevancia, se concreta en cuanto indicador, en el número de países socios que evalúan sus progresos mutuos poniendo en práctica los compromisos acordados sobre eficacia de la ayuda. Esto exige sistemas de evaluación más eficientes y generalizados. Por cierto, la transparencia es el aspecto más repetido 
en este apartado. Con transparencia, la confianza mutua se incentiva. Y con confianza y transparencia la corrupción -enemigo número uno de este principiotenderá a reducirse.

Los principios de París, hoy tan universalmente aceptados, constituyen un avance indiscutible. No seremos nosotros quienes discutamos su oportunidad, relevancia

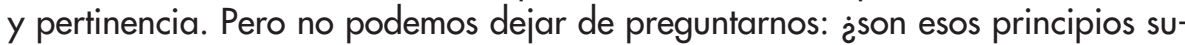
ficientes? ¿es eso todo lo que hemos aprendido en el mundo sobre desarrollo y cooperación al desarrollo? ¿̇representan esos principios la meta más avanzada a la que podemos llegar hoy en nuestra forma de concebir el camino hacia el desarrollo? Estas preguntas nos llevarían a una reflexión más de fondo: ¿̇cuáles podrían ser los componentes fundamentales de un modelo de desarrollo y su correspondiente reflejo en un modelo de cooperación al desarrollo? No pretendemos tener las respuestas a todas estas preguntas, pero aportaremos un par de sugerencias, en forma de dos nuevos principios a añadir a los anteriores:

- Hablaríamos de un principio de autonomía: se trataría con él de dotar a los países en desarrollo de libertad efectiva para que sean ellos los que formulen sus políticas internas. Esta autonomía no es actualmente posible en el marco de la OMC y sus reglas.

- Y propugnaríamos también un principio de articulación. Es algo distinto de la armonización de que se habló antes, ya que se trataría de articular entre sí los grandes bloques de políticas que formulan los gobiernos de los países en desarrollo.

Es más, tampoco basta con detenerse en los principios. Porque una cosa son los principios y otra su aplicación. De ahí que para cada uno de esos principios se establecieran metas concretas, evaluables. Y hoy, cuando ya ha transcurrido un tiempo suficiente desde 2005, cabe preguntarse hasta qué punto esos "buenos deseos" se han hecho realidad.

Precisamente a evaluar el grado de cumplimiento de la Declaración de París se consagró la Cumbre de Accra (Ghana) de septiembre de $2008{ }^{10}$. Este nuevo Foro de Alto Nivel concluyó con la Agenda de Acción de Accra, concebida como una fuente de energía adicional para profundizar la puesta en práctica de la Declaración de París. Pero, en contraste con el acuerdo de 2005, la Agenda de Accra

\footnotetext{
10 Seguimos a NiLS-SJARD SCHULz (2008) "De Accra al 2011 : Perspectivas para la gobernanza global de la ayuda - Área de Acción Humanitaria y Desarrollo", Fundación para las Relaciones Internacionales y el Diálogo Exterior (FRIDE), www.fride.org
} 
no establece plazos para la mayoría de sus compromisos: de ahí que resultará difícil de poner en práctica a nivel de los países y agencias. También se formularon algunas mejoras en la formulación y puesta en práctica de los compromisos de París. No podemos entrar aquí en sus detalles.

Según la valoración sobre la AOD que realiza FRIDE en su foro virtual abierto"1, dos son las conclusiones principales que se pueden extraer de este foro. Por una parte, se ha fortalecido la posición de los países del Sur, mientras que los progresos de los donantes son más bien desiguales: entre los primeros hay una mayor conciencia de la necesidad de superar la dependencia de la ayuda y se sienten más preparados para ello. En segundo lugar, han aparecido fricciones entre los países donantes: los miembros de la Unión Europea se han mostrado más dispuestos al diálogo político y a concretar sus obligaciones como donantes, que Estados Unidos y Japón que se mostraron más inflexibles en sus planteamientos. Así se puso de manifiesto en Accra, donde la postura de la Unión Europea encontró una valoración muy positiva por parte de los países del Sur y de la sociedad civil, donde por vez primera ésta, gran ausente todavía en París, fue incluida en la agenda.

En pocas palabras, más allá de los avances realizados en los planteamientos doctrinales, se puede razonablemente dudar de si la comunidad donante está preparada para los profundos cambios dibujados en la Agenda de Accra. Por ejemplo, se achaca al sistema internacional de ayuda al desarrollo de carecer de una plataforma adecuada y legitimada (reconocida) de acción conjunta de donantes y socios desde la que gobernar el régimen de la ayuda: mientras en Accra se ponía mucho énfasis en que no fueran sólo los donantes los que definieran la agenda, se constata cómo este campo sigue estando dominado por un "área gris", poco precisa y regulada, de colaboración entre el Banco Mundial y el mencionado $C A D$ de la OCDE, que dificulta la implicación efectiva de los nuevos actores de desarrollo y limita las voces de los países receptores, cada vez más organizados. Las futuras deliberaciones deberán dedicar cierto esfuerzo a la definición de la naturaleza, la legitimidad y el mandato del Grupo de trabajo sobre eficacia de la ayuda del CAD de la OCDE. La cosa se complica por el desarrollo creciente de la ayuda Sur-Sur, de países no pertenecientes a la OCDE (por ejemplo, Cuba,

\footnotetext{
${ }^{11}$ FRIDE es un think tank con sede en Madrid, que reflexiona sobre los principales asuntos internacionales, investiga en áreas de paz y seguridad, derechos humanos, promoción de la democracia, desarrollo y ayuda humanitaria, e interviene en el debate entre organismos gubernamentales y no gubernamentales, todo ello a partir de una concepción arraigada en los valores democráticos de la justicia y la igualdad.
} 
Venezuela, Brasil, China e India) ${ }^{12}$ y que no pasan los controles del CAD de la OCDE ni se someten a sus normas y criterios de evaluación.

\section{I.3. Nuevos mecanismos: los programas, los fondos globales, la ayuda presu- puestaria y el enfoque sectorial ampliado}

Paralelamente a esta evolución de los principios comúnmente aceptados acerca de la eficacia de la ayuda, y muy relacionado con ellos, se ha ido extendiendo el uso de nuevos mecanismos e instrumentos de ayuda, potencialmente más eficaces. Pasamos revista brevemente a algunos de ellos.

Aunque los proyectos concretos de desarrollo siguen siendo necesarios, los enfoques más solventes privilegian los programas, su financiación y ejecución. Se les valora porque están dotados de mayor flexibilidad y tienen un mayor alcance temporal. En este sentido, las agencias y ONGD de mayor dimensión y mejor organizadas suelen beneficiarse de convenios con los financiadores, sobre todo públicos, para plantear acciones combinadas y multisectoriales en el terreno, superando el enfoque de proyectos individuales y de corto plazo que ofrece sin duda resultados de desarrollo menos satisfactorios ${ }^{13}$.

Otra tendencia hoy preponderante es la de considerar el canal "de Estado a Estado", la llamada ayuda presupuestaria (budget support), como la vía más eficaz para hacer llegar los recursos a países de renta baja. Esta tendencia es vista con cierta preocupación, de la que nos hacemos eco, puesto que conlleva algunos riesgos como la burocratización de las políticas nacionales de lucha contra la pobreza o el replanteamiento de los recursos disponibles por las diversas formas de iniciativa social local, las organizaciones de la sociedad civil o las instituciones locales ${ }^{14}$.

${ }^{12}$ Cfr. C. XALMA (2008) II Informe de la Cooperación Sur-Sur en Iberoamérica, Estudios SEGIB 3, Secretaría General Iberoamericana (SEGIB), octubre 2008, 150 pp. Cuba resulta ser el país que tiene más proyectos de ayuda Sur-Sur (aunque sus criterios de medida de esa cooperación no coincidan con los del CAD de la OCDE).

${ }^{13}$ Así sucede en el caso español; la AECID suscribe convenios de este tipo con las ONGD más importantes, en ciertas condiciones y siguiendo protocolos que no es del caso analizar en este lugar.

${ }^{14}$ Véase Consejo Pontificio Justicia y Paz, l. c. 
En la misma línea, otro elemento metodológico renovado es el llamado enfoque sectorial ampliado (Sector Wide Approach) ${ }^{15}$, que orienta los fondos de la cooperación hacia determinados sectores de prioridad social, como educación y sanidad, sin entrar en pormenores de proyectos concretos. Se deja entonces que sea el país receptor -con la correspondiente auditoría- quien decida acerca de la aplicación concreta de dicha ayuda. En el fondo, es una forma de aplicar los principios fundamentales de la Declaración de París.

Pongamos un ejemplo muy significativo, el caso de Nicaragua, por la enorme cantidad de ayuda recibida en términos relativos en las últimas tres décadas. Un grupo destacado de países donantes (Dinamarca, Finlandia, Noruega, Suiza y Suecia) constituyeron en marzo 2006 un fondo común para ser aplicado a acciones en materia de desarrollo rural. Se aplica en este caso el principio de alineación de la cooperación externa en ese fondo común: varios países alinean "armonizadamente" sus apoyos financieros con las prioridades del gobierno; estamos además ante un enfoque sectorial ampliado, considerando "sector" al desarrollo rural ${ }^{16}$.

\section{I.4. La financiación del desarrollo. La Cumbre de Doha (2008)}

En este foro se reunieron más de 250 organizaciones y redes de todo el mundo con el objetivo de revisar las metas que se plantearon en la cumbre anterior de Monterrey (2002). Si la Cumbre del milenio había definido los objetivos, la cumbre de Monterrey vino a concretar los medios y los compromisos financieros para alcanzarlos. A principios de diciembre de 2008, seis años después, en Doha (Qatar) se trataba de revisar y evaluar esos compromisos.

Paralelamente, y como ocurriera en ocasiones semejantes, se constituyó un Foro de la sociedad civil, formado principalmente por ONGD. En él se consideró que estábamos ante una oportunidad perfecta para tratar los problemas estructurales

\footnotetext{
${ }^{15}$ Véase R. Anson - P. Pfaumann (2006) El rol del Enfoque Sectorial Ampliado para el Desarrollo Rural Sostenible en Centroamérica, San José de Costa Rica, RUTA (Unidad Regional de Asistencia Técnica), cfr. <www.ruta.org>. Cfr. también: G. FerReRO y DE LOMA-OsoRIO (2008) Apoyando los procesos de desarrollo. Enfoques y métodos para una ayuda inclusiva, Madrid, Fundación Carolina-CeALCl, Documento de trabajo 17, 209 pp. Documento disponible en <www.fundacioncarolina.es>.

${ }^{16}$ Desgraciadamente en el caso que nos ocupa, dos de los países estarán en fase de salida del fondo común en 2009. Por otra parte, este ejemplo constituye una excepción, ya que el grueso de los apoyos de la cooperación externa hacia las instituciones públicas y privadas del ámbito rural, continúan bajo esquemas bilaterales.
} 
que habían llevado a la crisis económica mundial, que deja a los más pobres aún más desprotegidos.

Una vez más, sin embargo, parece que se ha desaprovechado la oportunidad. Y son muchas las organizaciones solidarias que han manifestado su desilusión por los resultados de Doha. En efecto, los gobiernos participantes en esa cumbre no han sido capaces de fijar metas tangibles para acabar con la pobreza, ni de arbitrar medidas concretas. Es cierto que el contexto de la crisis era el menos favorable para llegar a conclusiones relevantes y operativas ${ }^{17}$. De hecho, se constata una disminución significativa en los últimos años de la ayuda global al desarrollo a escala internacional. Son muchos los países (España es, por ahora, una excepción) que han rebajado el listón de su contribución ${ }^{18}$ : según los datos últimos consolidados correspondientes al año 2007, la ayuda de la comunidad internacional a los países en desarrollo ha descendido un $9 \%$ respecto a 2006 . Gran parte de los 50.000 millones de dólares adicionales comprometidos en la reunión del G-20 de Gleneagles no se han desembolsado y la Unión Europea reduce su ayuda del 0,51 al 0,49\% del PNB. Como declaraba Ariane Arpa, directora de INTERMÓN-OXFAM, al presentar su último informe ya citado:

Mucho nos tememos que si esta tendencia a la baja de la ayuda al desarrollo internacional se consolida este año 2008, como parecen indicar los datos, podemos estar ante un tsunami humanitario, como apuntaba el responsable de la FAO recientemente.

Como resumen de todo este apartado sobre el contexto internacional de la ayuda, se han perfeccionado los enfoques, se han formulado principios loables, se ha alcanzado cierta madurez doctrinal, no faltan las buenas intenciones, existen mejores mecanismos, se multiplican los compromisos,... pero la ayuda disminuye. No parece una buena manera de aplicar la Declaración de París.

\section{La cooperación española: cantidad y calidad}

Habría que empezar diciendo que se trata de un área significativa en el planteamiento que ha hecho el presidente Rodríguez Zapatero de su política exterior.

17 Cf. Consejo Pontificio Justicia y Paz, l. c.

${ }^{18}$ El conjunto de los donantes han rebajado su aportación al desarrollo debido, principalmente, a que en ejercicios pasados condonaron deuda externa de Irak o Pakistán, engordando así artificialmente su AOD. 
No sólo ha cambiado el nombre del Ministerio de Asuntos Exteriores (ahora se llama Ministerio de Asuntos Exteriores y Cooperación), sino que ha manifestado una clara voluntad de elevar el rango de España en este ámbito, a pesar de los desequilibrios que podría causar en otros más estrictamente diplomáticos de nuestra política exterior. Da la impresión que este gobierno otorga a la política de cooperación el carácter de pieza clave de su políica de acción exterior, queriendo superar una cierta retórica tradicional, en particular en relación con los países menos desarrollados; y quiere transformar esta política en un conjunto de actuaciones de desarrollo que comportan desembolsos económicos, compromisos y prioridades mensurables y evaluables.

Tomando como referencia un horizonte un poco más amplio que el del último gobierno, hay que reconocer que en la cooperación española se han producido en estos últimos años avances considerables.

A continuación proporcionamos alguna información y reflexión sobre los aspectos sugeridos por el título de este apartado: evolución cuantitativa y cualitativa de la ayuda española al desarrollo ${ }^{19}$.

\section{I. La evolución de la cantidad: más cooperación ${ }^{20}$}

En los últimos 25 años España ha pasado de la condición de receptor de ayuda oficial al desarrollo (AOD) a la de donante. El Gráfico 1 permite apreciar la evolución de la aportación española en términos relativos entre 1990 y 2007 . Es notorio en él el incremento experimentado en el último periodo ${ }^{21}$. Si la ayuda española había alcanzado la cifra de 2.000 millones de euros en 2004, en 2006 estaba ya en poco más de 3.000 millones, y en 2007 llegó a 3.747 millones de euros, lo que representa un $0,37 \%$ del PNB (no se alcanzó la cantidad presupuestada, que

\footnotetext{
19 Para más información puede consultarse: S. MEYER (2007) o los informes periódicos de INTERMÓNOXFAM sobre ayuda al desarrollo. Véase también la evaluación sintética de J. A. Alonso, "España en guerra contra el hambre", El País, 5-VII-2008.

20 La mayor parte de la información que presentamos procede de los citados informes anuales de INTERMÓN-OXFAM.

${ }^{21}$ El incremento atípico experimentado en 2001 tuvo su origen en una operación muy concreta y excepcional (condonación de una deuda contraída por Guatemala para la financiación de CELGUSA: "Celulosas de Guatemala SA"); véase una explicación más detallada en INTERMÓN-OXfaM (2003) La Realidad de la Ayuda 2002-2003.
} 
ascendía al 0,42\% del PNB $)^{22}$. Como resumen cabe decir que España es el país de la OCDE que más aumentó su ayuda en estos años ${ }^{23}$.

\section{GRÁFICO 1}

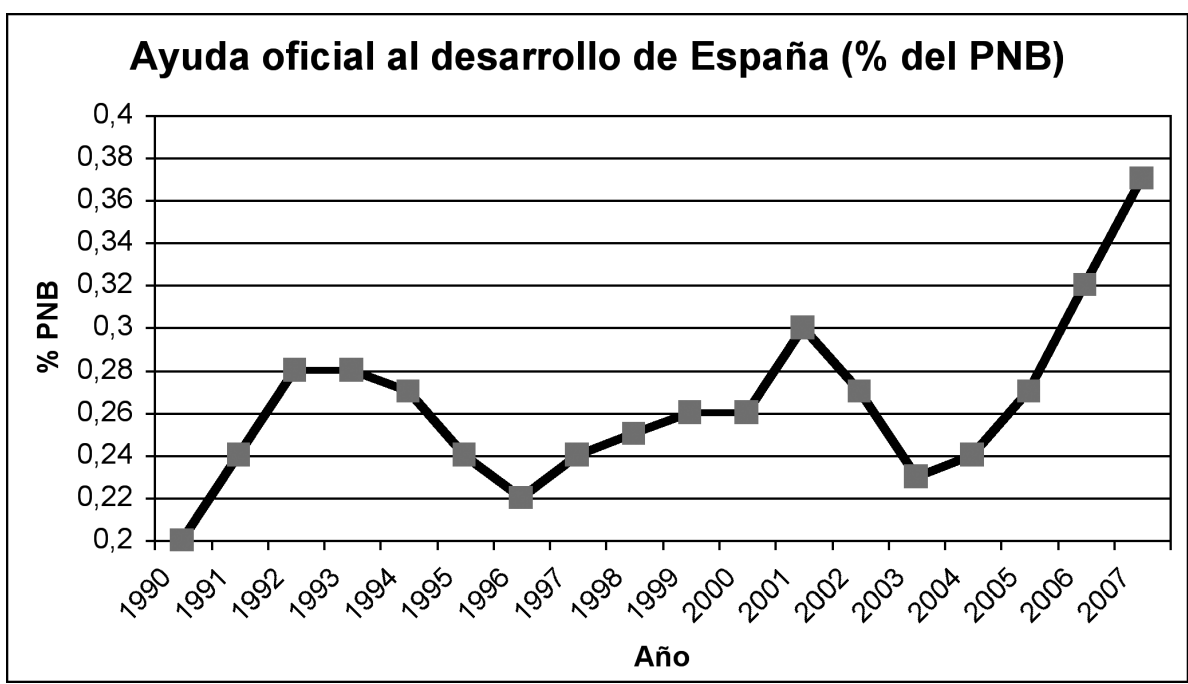

Efectivamente, el compromiso del presidente del Gobierno en enero de $2007^{24}$ era duplicar la ayuda al desarrollo, en cuanto era una prioridad de la políitica exterior.

${ }^{22}$ Estas cifras se calculan siguiendo una metodología rigurosa acordada en el seno del Comité de Ayuda al Desarrollo de la OCDE.

${ }^{23}$ Para mejor valorar esa cifra-considerable en términos absolutos- pueden ser útiles esta comparación: en ese mismo año 2007, los fondos destinados a la cobertura de las prestaciones por desempleo en nuestro país ascendieron a más de 14.000 millones de euros, cuatro veces más que la ayuda al desarrollo. Aún así algunos expertos alertan sobre la inconveniencia de un precipitado aumento en la ayuda, pues no hay capacidad en las ONGD y en otras instituciones apara asumir ese incremento presupuestario en breve plazo, sin realizar antes las adaptaciones o innovaciones estructurales tanto de los agentes del desarrollo como en los países receptores. No es fácil gastar tanto dinero en poco tiempo, si antes no se preparan quienes deben responsabilizarse de esa gestión. Por otro lado un aumento rápido del dinero presupuestado hace que todas las agencias tengan la tendencia de moverse en busca del dinero, quedando afectado el camino del multilateralismo.

${ }^{24}$ El País, 15 de enero de 2007. 
Para él, el avance de España en camino de convertirse en uno de los grandes donantes tenía un altísimo valor ético.

Para Miguel Ángel Moratinos, Ministro de Asuntos Exteriores y Cooperación, existía una convicción firme, que recogía en la siguiente afirmación: Sé que mi gestión será juzgada en relación con este nuevo imperativo moral y político [la reducción de pobreza], que es una de las señas de identidad de nuestro país ${ }^{25}$.

La cifra de 2007 sitúa a nuestro país en el séptimo lugar entre los donantes del Comité de Ayuda al Desarrollo (CAD) de la OCDE en términos absolutos y en el decimoprimero si lo miramos en términos relativos a su riqueza. La meta internacional del 0,7 sólo ha sido superada por los siguientes países: Noruega, Suecia, Luxemburgo, Dinamarca y Países Bajos; sin llegar al 0,7, pero por encima de España, se encuentran Irlanda, Austria, Bélgica, Finlandia, Francia y Suiza. España "empata" con Alemania y Suiza en ese valor del 0,37; por debajo de dicha cifra siguen, por este orden, Reino Unido, Australia, Canadá, Nueva Zelanda, Portugal, Italia, Japón, Grecia... y Estados Unidos (estos últimos con sólo un $0,16 \%$ ).

Para valorar el avance de España hay que tener en cuenta que se partía de un nivel muy bajo y que el proceso exige también mejorar las estructuras organizativas $y$, en general, la "cultura de la ayuda". En el horizonte está el compromiso que mantiene el gobierno de alcanzar la cifra del 0,7\% en 2012, al final de la presente legislatura, un objetivo difícil de lograr ya que supone duplicar prácticamente la cantidad actual. Además, ya en 2007 ha habido un desfase derivado de la falta de capacidad de ejecución de lo presupuestado, así como de la dificultad de cuantificar efectivamente todo lo ejecutado por los distintos actores ${ }^{26}$.

El incremento de la ayuda española se debe fundamentalmente al aumento de las contribuciones de España a organismos multilaterales (Naciones Unidas, principalmente), que supusieron en 2007 más del 60\% del total de nuestra AOD. España destinó sólo a las Naciones Unidas 929 millones de euros en ese ejercicio, la mayor aportación de su historia, llegando a duplicar la ayuda multilateral a lo largo de la legislatura.

${ }^{25}$ Congreso de los Diputados, Diario de sesiones, n. 788 (1 1 de marzo de 2007).

${ }^{26} \mathrm{El}$ compromiso del gobierno de llegar a la cifra del 0,7\% del PNB en 2012 pasaría por el hito intermedio del 0,56\% en 2010, según el III Plan Director (cfr. p. 12) y en virtud de los compromisos adquiridos en el seno de la UE. INTERMÓN-OXFAM había propuesto una senda de crecimiento muy parecida. Obviamente, en tiempos de recesión, la cantidad de ayuda en términos absolutos puede estancarse o incluso disminuir, al hacerlo la base de cálculo, el PNB total. En todo caso, será realmente difícil que las cifras reales de este crítico año 2009 y siguientes cumplan lo prometido. 
Una parte sustancial del incremento reciente de la ayuda se debe también a la contabilización (admitida por el CAD de la OCDE) de las operaciones de condonación de deuda como ayuda al desarrollo. Sin entrar a considerar si esas operaciones deben ser así computadas, éste no deja de ser un elemento perturbador -por su inestabilidad-a la hora de valorar las tendencias de fondo del crecimiento cuantitativo de la ayuda.

Pero no todo se juega en la cantidad de ayuda. Como indicaba Leire Pajín, Secretaria de Estado de Cooperación del primer gobierno Zapatero:

La meta no es alcanzar el 0,5 de la AOD a cualquier precio, sino hacerlo de una manera que permita garantizar la sostenibilidad y calidad del compromiso solidario de España, calidad reclamada por la sociedad que trabaja en la cooperación ${ }^{27}$.

\subsection{El reto de la calidad: mejor cooperación}

Aumentar el volumen de ayuda es una cosa; hacerlo de forma eficiente y con resultados satisfactorios es otra. Dicho de otra manera, más cantidad de fondos no significa automáticamente mejor cooperación. Ahora bien, parece indiscutible que se está produciendo un lento acercamiento de los rasgos cualitativos de la cooperación española a los vigentes entre los mejores donantes.

\section{a) Aspectos positivos}

Para empezar, según el informe tantas veces citado de INTERMÓN-OXFAM, en la AOD española destacan tres rasgos positivos:

La ayuda española está viviendo su etapa de crisálida y ya manifiesta lo que deben ser sus rasgos adultos: una ayuda más multilateral, más social y más africana.

a) La ayuda es más multilateral porque la contribución a organismos multilaterales (por este orden: Unión Europea, Grupo Banco Mundial, Naciones Unidas y

\footnotetext{
${ }^{27}$ En la Comisión Internacional de Desarrollo del Congreso, Diario de sesiones, Congreso de los Diputados, 808, 19 de marzo de 2007. Véase el análisis de S. MEYER (2007) La Cooperación Española para el Desarrollo: ¿aspiraciones hechas realidad?, Fundación para las Relaciones Internacionales y el Diálogo Exterior (FRIDE), Documento de trabajo, $n^{\circ} 40$, nota 1, p. 1. Junto con los informes anuales de INTERMÓN-OXFAM sobre "La realidad de la ayuda", son dos evaluaciones bien documentadas, con criterio y que nos merecen mucha confianza.
} 
otros organismos multilaterales de desarrollo) ha aumentado considerablemente, hasta llegar al $60 \%$ del total de la AOD española. Ese ha sido el secreto del alto ritmo de crecimiento de nuestra ayuda en los últimos años y constituye un cambio estratégico que merece algunas consideraciones adicionales. Dado que se trata de aportaciones directas a dichas instituciones y que la administración de esa ayuda no corresponde a los organismos españoles (por ejemplo, a la AECID), ni se distribuye a través de las Oficinas técnicas de cooperación (OTC) de la AECID en los países receptores, o a través de las ONGD, su crecimiento puede hacerse de forma más rápida. Este aumento lleva aparejado un mayor peso político español en los organismos así financiados, pero también un mayor compromiso de España con los errores y disfunciones (de fondo y de forma) que esos organismos puedan cometer. En particular, es cada vez más significativa la participación de nuestro país en la aportación financiera y en la definición de políticas de cooperación de la Unión Europea; acuerdos como el llamado "Consenso europeo de Desarrollo" de diciembre de $2005^{28}$ comprometen a España en una vía de mejora cualitativa de su cooperación. De este modo España ha pasado a una posición de liderazgo en el sistema internacional de ayuda, pero no es evidente que esté preparada para aprovechar plenamente esta oportunidad de promover cambios. Por eso es absolutamente esencial la definición -prevista en el III Plan Director- de una estrategia multilateral con el fin de minimizar el peligro real de destinar montos muy elevados a iniciativas poco meditadas.

b) La ayuda española es también más social, por cuanto se dedican más fondos a servicios sociales básicos (esencialmente salud, educación, acción humanitaria etc.) en aplicación de un antiguo compromiso de destinar a ellos el 20\% de AOD, asumido por los donantes y los receptores en la Cumbre Social de Copenhague, a la vez que los segundos se comprometían a destinar el $20 \%$ de su presupuesto a servicios sociales básicos.

c) La ayuda es, por fin, más africana porque el incremento de la AOD multilateral permite orientar más fondos hacia África-a través de los organismos referidosequilibrando la excesiva orientación tradicional bilateral hacia América Latina y, en consecuencia, a países de renta media. Es cierto que África es la región del mundo donde se concentran los problemas de falta de desarrollo con mayor intensidad y eso podría justificar que se dirigieran a ese continente recursos que antes se dirigían a otras zonas, América Latina por ejemplo. Sin embargo, esta tendencia

\footnotetext{
${ }^{28}$ Este consenso manifiesta el firme compromiso de la Unión Europea con la coherencia de políticas para alcanzar los Objetivos del Milenio y con el incremento del volumen de AOD necesario para su consecución.
} 
ha de gestionarse con sumo cuidado: porque el obstáculo último al desarrollo es la falta de equidad, y ésta se da también en países de ingresos medios, como son los latinoamericanos ${ }^{29}$.

Es de destacar que, sin alcanzar todavía el nivel de los países líderes (como los del llamado grupo Nordic $+{ }^{30}$ ) con más larga tradición de cooperación, la política de cooperación española ha dado pasos sustanciales de mejora. Al aumentar la cultura y la importancia de la cooperación al desarrollo, nos encontramos con un buen patrimonio analítico y crítico de la cooperación, que va permitiendo avances notables en la concertación a nivel doctrinal de los diferentes actores de la cooperación (ONGD y medios académicos). Nos hemos acercado, desde el punto de vista conceptual, a los mejores planteamientos de los donantes más acreditados: así lo ha reconocido el propio CAD de la OCDE al evaluar la cooperación española. Por otro lado, existen excelentes análisis y valoraciones, procedentes de entidades académicas o similares especializadas o a partir de servicios de estudios de ONGD ${ }^{31}$. Y existe además en España una conciencia de la necesidad y conveniencia de la ayuda al desarrollo: lo demuestran los estudios de opinión ${ }^{32}$.

Por otro lado, la búsqueda de consenso y el diálogo han sido la tónica dominante tanto en el Consejo de Cooperación como en la Comisión Internacional de Desa-

${ }^{29}$ En América Latina el nivel de desigualdad es muy alto, lo que explica la existencia de cerca de 200 millones de pobres (más de un $40 \%$ de la población). La existencia de altos niveles de pobreza en un país de ingresos medios puede ser indicador de un crecimiento no inclusivo, o concentrado en determinados sectores y territorio, y sin igualdad no puede decirse que haya desarrollo humano. Lo que sí puede ser cierto es que las políticas de ayuda al desarrollo habrán de ser distintas en ambos casos: en estos países de ingresos medios quizás se requiere una cooperación relacionada con la naturaleza y la calidad de las políticas internas de dichos países, y no tanto con la cantidad de AOD.

${ }^{30}$ Este grupo de donantes reúne a Dinamarca, Noruega, Suecia, Finlandia, Irlanda, Países Bajos y el Reino Unido (la "crema" de los países donantes, se podría decir). Además se han adherido Alemania y Canadá por semejanza de planteamientos. España aspira a integrarse en ese grupo ampliado, al que se denominaría Nordic++.

${ }^{31}$ Véanse, entre otras, las reflexiones periódicas del Instituto Complutense de Estudios Internacionales (ICEI Paper, Working Papers y Policy Papers). Los informes anuales de Intermon-Oxfam sobre la realidad de la ayuda aportan una evaluación insustituible sobre la cantidad y la calidad de la ayuda. Un trabajo de síntesis que nos ha parecido excelente es el ya citado de S. MEYER (2007).

${ }^{32}$ Cfr. G. Angulo (2007), "Opinión Pública, Participación Ciudadana y Política de Cooperación en España", Working Papers 07, Instituto Complutense de Estudios Internacionales (ICEI), Universidad Complutense de Madrid, WP 03/07, 37 pp. 
rrollo del Congreso de los Diputados, no tan habituales en el segundo Gobierno del PP (2000-2004).

También ha aumentado considerablemente la ayuda descentralizada de comunidades autónomas, ayuntamientos y otros entes locales ${ }^{33}$. El gran reto consiste en introducir coherencia y armonizar tantas y tan diferentes formas de actuar, con frecuentes solapamientos o contradicciones. Correspondería a los órganos centrales de la cooperación española introducir coherencia entre tantos actores con tan diferentes estilos y motivaciones y evitar disfunciones importantes como la llegada a los mismos lugares y en los mismos sectores, de ayudas procedentes de diferentes administraciones ${ }^{34}$.

Asimismo, está anunciada la reforma de la vigente Ley de Cooperación Internacional de 1998, durante el periodo de vigencia del III Plan Director (2009-2012), al que nos referimos en seguida, para adaptarla a las nuevas circunstancias. Otros objetivos propuestos para la citada reforma serían: la inclusión de nuevos agentes de cooperación, una apuesta más clara por la cooperación multilateral y por determinados sectores. Para llevar a cabo esta reforma habrá que contar, como ocurrió con la anterior en circunstancias políticas diferentes (primer gobierno de Aznar), con la participación, el consenso y el apoyo de los distintos agentes y sectores políticos y sociales.

Todavía se pueden mencionar otros avances normativos: se ha puesto en marcha la Ley de Deuda ${ }^{35}$; fue aprobado el Estatuto del Cooperante, aunque no ha satisfecho plenamente a los actores involucrados ${ }^{36}$; está en marcha la reforma tan esperada de la $\mathrm{AECID}^{37}$, aunque según algunos todavía queda mucho por hacer.

\footnotetext{
${ }^{33}$ Se incrementó en un 15,6\% en 2007, alcanzando los 512 millones de euros. Este incremento ha sido especialmente importante en las comunidades autónomas, que ha sido del $20 \%$ con respecto a 2006.

${ }^{34}$ Un hito en el proceso de coordinación de la cooperación autonómica fue la celebración en julio de 2008 del I Encuentro de Comunidades Autónomas, liderado por la Comunidad de Aragón.
}

${ }^{35}$ El marco fundamental de la gestión de deuda externa viene dado por la Ley 38/06 de 7 de diciembre reguladora de la gestión de la deuda externa (conocida como "Ley de deuda"); cfr. BOE 293 de $8 / 12 / 06$. Por primera vez se vincula la deuda externa con el desarrollo.

${ }^{36}$ Cfr. RD 519/2006 de 28 de abril, BOE 114 de 13/5/06. A pesar de sus limitaciones, constituye un avance hacia el reconocimiento de las especificidades de los cooperantes.

${ }^{37}$ Su nuevo Estatuto fue aprobado en octubre de 2007. Cf. Real Decreto 1403/2007 de 26 de octubre. BOE 283 de $26 / 11 / 2007$. 


\section{b) Aspectos negativos}

Quizás la valoración anterior ha parecido demasiado positiva. Sin embargo, no todo son luces. Hay también sombras ${ }^{38}$.

En primer lugar, y a pesar del incremento general de la ayuda, estamos todavía lejos de la meta del 0,42\% de PNB, comprometida por el Gobierno para el año 2008. Este desfase se explica, en parte, por el limitado grado de ejecución en 2007, que fue de sólo un $87 \%$ de la ayuda prevista, considerablemente menor que el de años anteriores, que superaba el $93 \%{ }^{39}$.

INTERMÓN-OXFAM afirma que, hasta la fecha de su informe, el sistema de cooperación español sigue en estado larvario, por cuanto está encontrando resistencias a las reformas que necesita para madurar en eficacia: ni la reforma de la AECID está surtiendo los efectos deseados, principalmente por problemas de capital humano; ni los órganos consultivos alcanzan el dinamismo que necesitan; ni se han aplicado suficientemente los nuevos instrumentos (sobre todo el de apoyo presupuestario directo, que tanto ahorra en burocracia e incrementa la eficacia ${ }^{40}$ ); ni se ha avanzado suficientemente en la coherencia de políticas, más allá de la coherencia de instrumentos de cooperación ${ }^{41}$.

Por otro lado, es cierto que la ayuda española ha avanzado en las metas de eficacia establecidas por el CAD, pero sigue quedando por debajo de la media

\footnotetext{
${ }^{38}$ Seguimos también aquí el citado informe de INTERMÓN-OXFAM.
}

${ }^{39}$ También se pueden abrigar serias dudas acerca nivel de ejecución de los 5.500 millones de euros presupuestados en la partida de AOD para 2008, lo que supone unos 1.700 millones más que el año 2007. También es llamativo que, para 2009, el gobierno ha congelado el crecimiento, presupuestando la misma cantidad que para 2008.

40 Según Intermón OXfam, I. c., en España el apoyo presupuestario directo recibe menos del $1 \%$ del total de nuestra ayuda, cuando debería representar al menos el $10 \%$.

${ }^{41}$ Un punto muy "caliente", relativo a la coherencia (o, mejor, incoherencia) de las políticas, es la proliferación de ventas de armas fabricadas en España a países pobres en conflicto bélico, al tiempo que nuestro país emprende importantes gestiones diplomáticas en los escenarios de esos conflictos para la consecución de la paz: en este ámbito, la contradicción entre el discurso y los hechos es clamorosa. Otro caso de falta de coherencia es el estancamiento de las negociaciones agrarias en la ronda Doha de la OMC: nos referimos con más detalle a esta cuestión en el anterior editorial citado: CONSEJO DE REDACCIÓN (2008), "El hambre: ¿̇tsunami silencioso?", I. c. en nota 1. Lo mismo cabe decir de las restricciones impuestas por los llamados "Aspectos de los Derechos de Propiedad Intelectual relacionados con el Comercio" (ADPIC o, en inglés, TRIPS). 
de los donantes en prácticamente todos los indicadores. El ritmo de avance de las reformas imprescindibles para garantizar la calidad de la ayuda no está siendo tan rápido como el crecimiento de los recursos, y la crisis económica va a intensificar las resistencias al progreso cualitativo hasta poner en peligro la gestión del 0,7\% (suponiendo que se alcance...). La mejora cualitativa de la ayuda es fundamental para la eficacia medida en resultados, pero también para que el sistema español pueda seguir creciendo cuantitativamente.

Quedan pendientes también dos reformas importantes: la de los créditos del Fondo de Ayuda al Desarrollo (créditos FAD-"la oveja negra" de la cooperación española) y la de la Compañía Española de Seguros de Crédito a la Exportación (CESCE).

Los créditos FAD se dan a países con dificultades económicas, en mejores condiciones financieras que las que ofrece el mercado. Este hecho permite que se puedan contabilizar como Ayuda Oficial al Desarrollo (AOD). Este hecho ha llevado a que los FAD hayan llegado a significar más de la mitad de la AOD bilateral española. En estos momentos, aunque no lleguen al $5 \%$ del peso total de la AOD bilateral, siguen suponiendo más del $50 \%$ del total de la deuda que deben los países del Sur a la administración española.

Los créditos FAD constituyen el caso más significativo de "ayuda ligada": son créditos que se conceden a países con dificultades económicas para financiar inversiones y gastos realizados por empresas españolas en ellos, y que pueden contabilizarse como AOD por el hecho de que sus condiciones financieras son mejores que las que ofrece el mercado. En último término, el FAD sirve a dos intereses, cada uno legítimo en sí mismo pero difíciles de conciliar entre sí: la internacionalización de las empresas españolas y la ayuda al desarrollo. Por eso es necesario separarlos, de forma que los instrumentos para internacionalizar la empresa española no computen nunca como AOD; sería deseable además que este tipo de crédito se conceda sólo a los países de renta media, pero nunca a los más pobres y endeudados.

Por su parte, la CESCE, en la que participan los grandes bancos españoles, asegura las exportaciones españolas en aquellos países con un alto riesgo. Cuando una operación comercial resulta fallida, la CESCE paga a la empresa exportadora española y al banco prácticamente la totalidad del importe de la operación, para reclamarlo después a la Administración del país donde se realizó la exportación. 
Por estas razones, las operaciones que ejecuta CESCE deberían considerarse como subvenciones encubiertas a la exportación ${ }^{42}$.

Existe aún otra tarea, que no es la menor ni la más sencilla: concluir la reforma emprendida de la AECID. La reorganización administrativa y la formación de los equipos humanos de los órganos de la cooperación, centrales y "en el terreno", pueden ser un cuello de botella en la mejora de la calidad de la cooperación española. Todavía queda mucho por hacer.

\subsection{Los planes directores de la cooperación española}

Un plan director es un documento de programación o estrategia plurianual (para el periodo de una legislatura) de la cooperación española al desarrollo; constituye, pues, un marco de actuación que, a su vez, se concreta en planes anuales (llamados PACl: "Plan anual de cooperación internacional"), componentes esenciales del ciclo de programación. Su importancia radica en que marca las pautas de lo que ha de ser la cooperación española en el periodo considerado. El Plan Director tiene por objetivo garantizar la oportunidad, coherencia, eficacia y eficiencia de la política pública de cooperación internacional para el desarrollo. Es el elemento básico de planificación cuatrienal y determina las líneas generales y directrices básicas, señalando objetivos y prioridades (estratégicas, horizontales, sectoriales y geográficas), y avanzando los recursos presupuestarios indicativos para ese periodo.

\section{Los dos primeros planes directores}

El I Plan Director (2001-2004) fue elaborado durante el segundo gobierno de Aznar, siendo Miguel Ángel Cortés Secretario de Estado de Cooperación. En contraste con la política de cooperación del primer gobierno del PP, valorada de modo bastante positivo por los sectores afectados, este primer plan fue duramente criticado por todos los actores españoles de la cooperación (ONGD, instancias académicas, etc.). Las críticas tenían que ver tanto con el fondo como con la forma, en particular, con el diálogo escaso que acompañó el proceso de su elaboración. El

\footnotetext{
${ }^{42}$ Cf. D. Gómez-Olivé-M. Torres (2008), "Cooperación entre Estadoy empresas. Ayudas a la exportación española y endeudamiento de otros países", Revista Pueblos, Asociación Paz con Dignidad (lunes, 24 de marzo de 2008); cf. también "FAD y CESCE. Los mecanismos generadores de deuda externa": Boletín de la campaña contra la deuda externa ¿Quién debe a quién?: Cf. <www.quiendebeaquien.org>
} 
propio Consejo de Cooperación emitió un informe negativo al respecto ${ }^{43}$. Dos eran las críticas principales de fondo: a) discontinuidad y marcha atrás con respecto a los planteamientos doctrinales y a la propia política de cooperación iniciada en la primera legislatura del propio gobierno del Partido Popular; b) excesiva vinculación entre la ayuda y la promoción de los intereses económicos y estratégicos españoles, relegando a un segundo plano el propósito básico que debe inspirar la ayuda, relacionado con la lucha contra la pobreza y el subdesarrollo, en sus muy diversas manifestaciones.

El II Plan Director (2005-2008), correspondiente ya a la primera legislatura del gobierno de Zapatero, recibió una valoración mucho más positiva por parte de los diferentes actores, tanto por su contenido como por los procesos seguidos en su elaboración y en su aplicación. Del mismo se destacaron los siguientes aspectos: el aumento significativo de los fondos asignados y su orientación preferente hacia sectores multilaterales y sociales; el desarrollo de un conjunto exhaustivo de herramientas de planificación, junto a una mayor transparencia en cuanto a objetivos; la mejora de las relaciones con la sociedad civil mediante un estilo de consultas más abierto que favorecía la calidad del debate público; el hecho de que la gestión de la deuda haya quedado sometida a los criterios del desarrollo; el importante liderazgo asumido por España en las propuestas de "co-desarrollo", que vinculan los fenómenos migratorios con el desarrollo, etc. Haber centrado toda la atención en la elaboración de planes ha retrasado las cuestiones de las reformas de la estructura de provisión de la ayuda y, sobre todo, de la Agencia Española de Cooperación Internacional ${ }^{44}$.

\section{Una primera aproximación al III Plan Director}

Este nuevo Plan Director, que se sitúa en estrecha continuidad con el II, se encuentra actualmente en la fase final de aprobación. Todo el proceso de su redacción ha estado marcado por la búsqueda del consenso y de la participación con un claro liderazgo técnico y político de la Dirección General de Planificación y Evaluación

\footnotetext{
${ }^{43}$ Véase: Grupo de eXPerTos del CONSEJO de COOPERACIÓN, “Dictamen sobre el borrador de Plan Director de la cooperación española 2001-2004", ( sin fecha, aproximadamente diciembre de 2000). Suscriben este dictamen los siguientes vocales del Consejo: María Luz Ortega, Alfonso Dubois, José Antonio Sanahúja, Carmen Cruz, Rafael Martinez Cortina, José Antonio Alonso. Cfr. <www.fongdcam.org>

${ }^{44}$ Hemos seguido la valoración de FRIDE, elaborada por S. MEYER, I. c.; puede verse también la de INTERMÓN OXFAM, I. c.
} 
de Políticas de Desarrollo (DGPOLDE) ${ }^{45}$. Su base fue una hoja de ruta, elaborada por la DGPOLDE, con el objetivo de "consolidar una política pública de desarrollo" centrada en las personas, aunque se puede considerar como punto de partida de este nuevo Plan, el "Pacto de Estado contra la pobreza", firmado en diciembre de 2007 por todas las fuerzas políticas parlamentarias.

El proceso de elaboración del Plan ha recorrido las siguientes etapas: en octubre 2008 salió a consulta pública el primer borrador del Plan Director 2009-2012, que es resultado de un borrador interno elaborado por la DGPOLDE, discutido previamente por los organizaciones de la sociedad civil y revisado por diversos ministerios; un segundo borrador, que incorporaba las sugerencias recibidas al primero, fue hecho circular en diciembre 2008; tras incorporar las enmiendas recibidas a este segundo borrador, el texto fue aprobado por unanimidad el 3 de febrero por el Consejo de Cooperación al Desarrollo, requisito previsto en la citada Ley de Cooperación; inmediatamente fue presentado al Consejo de Ministros, que lo aprobó el pasado 13 de febrero; el último paso consistirá en su presentación a la Comisión Internacional de Desarrollo del Congreso de los Diputados. La discusión y el refrendo parlamentarios del Plan serán el indicio más fehaciente del paso real de una política para la cooperación de Gobierno a una política de Estado.

La descripción detallada de los numerosos aspectos de interés contemplados en este tercer Plan no es posible aquí. La enumeración de los "ámbitos estratégicos de la política de desarrollo de la cooperación española", incluida en el capítulo 6 del borrador, consiste en una especie de prioridades metodológicas que acompañarán a las prioridades geográficas y sectoriales. Con ello se busca incorporar los principios de la Declaración de París a la política española de cooperación, adecuando ésta a la nueva arquitectura internacional de la ayuda. Dichos ámbitos estratégicos son:

- La asociación en el terreno: una ayuda eficaz y de calidad.

- El multilateralismo activo y eficaz.

- La coherencia de políticas para el desarrollo.

- La educación para el desarrollo.

- La investigación, innovación y estudios sobre el desarrollo.

${ }^{45}$ La DGPOLDE fue creada en la Secretaría de Estado de Cooperación Internacional (SECI) durante el II Plan Director para fortalecer el sistema de planificación y evaluación de la cooperación española; en octubre de 2007 se reformaba la Agencia Española de Cooperación Internacional al Desarrollo (AECID) para hacerla capaz de atender a nuevos retos geográficos presupuestarios e institucionales que nuestro sistema de cooperación demandaba. Es una reforma que todavía debe consolidarse. A diferencia de la AECID, la DGPOLDE no ejecuta, sino que planifica y evalúa; se produce de esa manera una cierta división de funciones no exenta a veces de conflictos. 
- El fortalecimiento de capacidades institucionales y humanas.

- La coordinación y complementariedad de actores.

Como valoración de conjunto puede decirse, no sólo que el III Plan Director representa un importante paso adelante en la formulación de una política de cooperación avanzada y coherente, sino además que se sitúa en continuidad con las intuiciones y mejoras más destacadas del II Plan. Ya en la hoja de ruta que preparó el gobierno para la elaboración de este nuevo Plan se insistía en un "mensaje de continuidad y profundización" en relación al Plan anterior, porque "la cooperación española no se podría permitir el lujo de cambiar de rumbo de manera significativa cada cuatro años ${ }^{\prime \prime 6}$. Efectivamente, creemos que así está sucediendo. ${ }^{47}$

Nos parece que el eje de este plan director es el paso de una política de cooperación a una política de desarrollo; dicho de otra manera, se busca que la eficacia de la ayuda se base en la obtención efectiva de los resultados de desarrollo. Esta propuesta queda clara a lo largo del documento, lo que contribuye a mejorar las orientaciones de planes anteriores.

Una valoración sintética y autorizada de la calidad de la ayuda fue realizada por el ya citado Comité de Ayuda al Desarrollo de la OCDE en su último informe de 2007 sobre la cooperación española. Pues bien, el III Plan Director ha pretendido explícitamente consolidar las líneas de avance e incorporar las recomendaciones sugeridas por el CAD:

España se ha propuesto metas muy ambiciosas para su cooperación al desarrollo hasta el año 2012. El Plan Director 2005-2008 establece notables mejoras con respecto a las políticas y prácticas anteriores, y España se enfrenta ahora al desafío de trasladar la visión de conjunto al terreno práctico. El apoyo político y el marco para la coherencia de las políticas son sólidos. Sin embargo, se necesita un uso más sistemático y estratégico para garantizar el progreso. España está aumentando rápidamente su volumen de ayuda y necesita mejorar su capacidad para prestar ayuda bilateral sin dispersar el esfuerzo. Un nuevo compromiso con África Subsahariana refleja un enfoque más centrado en la pobreza y ofrece nuevas oportunidades para la división de las tareas entre los donantes. La creciente ayuda multilateral española es cada vez más estratégica. El liderazgo político está impulsando reformas profundas en la organización y gestión para incrementar la eficacia

\footnotetext{
${ }^{46}$ INTERMÓN OXfAM, I. c., 15.

${ }^{47}$ La Coordinadora Nacional de ONGD (CONGDE) emitió una valoración final elogiosa: cfr.CooRdinadora ONG para el DesarRollo-España (2009), Documento de valoración de la Coordinadora de ONG para el desarrollo-España al III plan director 2009-2012. 13 de febrero de 2009. Cfr. <www. congde.org>
} 
de la ayuda que generan, a su vez, un proceso de cambio global en el sistema de ayuda. La eficacia de la ayuda está tomando impulso, a medida que España aplica sobre el terreno los principios de la Declaración de París. Pero la puesta en práctica exitosa de la agenda de eficacia de la ayuda dependerá de la conclusión del proceso de reforma. La estrategia de la acción humanitaria española refleja buenas prácticas a nivel internacional y ahora el país debería garantizar una mayor coordinación entre los actores humanitarios. ${ }^{48}$

Para concluir esta sumaria presentación valorativa de la cooperación española, podemos recordar cuáles son los grandes retos que el sistema estatal de cooperación va a afrontar en el próximo período ${ }^{49}$ :

- Mantenery consolidar el aumento cuantitativo de la AOD, para dar cumplimiento al compromiso reiterado por el presidente del Gobierno de alcanzar el 0,7\% del PNB al final de la legislatura, apoyado por todos los grupos parlamentarios.

- Hacer efectivamente compatibles las dos tendencias mencionadas: aumento cuantitativo y consolidación cualitativa. En la práctica, nos encontramos a mitad de camino en este proceso con importantes debilidades y riesgos a los que es necesario prestar la debida atención.

- Pasar de una política de cooperación a una política de desarrollo. Esto implica trascender la coherencia de políticas en su vertiente interna (centrada en la relación de unos instrumentos con otros dentro del sistema de ayuda) para abordar un reto mucho más ambicioso: convertir el III Plan director de la cooperación española en un plan integral de política española de desarrollo internacional. Ello nos llevará necesariamente a incorporar a nuestra política exterior una perspectiva más global.

Al llegar aquí nos queda todavía una pregunta: ¿no podríamos aspirar a más? Porque la incorporación a las tendencias internacionales en cooperación, sin duda un hecho positivo, introduce en la cooperación española algunos de los problemas que acompañan a la AOD internacional. ¿̇Habrá que renunciar a la aportación de nuevas ideas de la cooperación española para hacer más efectiva la cooperación con los países en desarrollo?

\footnotetext{
${ }^{48}$ OCDE (2007), España. Comité de ayuda al desarrollo. Examen inter pares, Ministerio de Asuntos Exteriores y Cooperación y OCDE, 11. Se trata de un "examen" independiente de la cooperación española realizado, aproximadamente, cada 5 años a todos los miembros del CAD de la OCDE; se cita literalmente el primer párrafo del informe que contiene un resumen de la evaluación.
}

${ }^{49}$ INTERMÓN-OXFAM, Informe $n^{\circ} 13$, p. 4. 


\section{Conclusión: en medio de la crisis, ¿queda espacio para la solidaridad?}

El que la comunidad internacional reaccione con más interés, agilidad y eficacia ante la crisis financiera que frente a la crisis eterna del desarrollo de gran parte del mundo es sólo la punta del iceberg del problema de fondo: el de la visión dominante del mundo, que incluye el modelo de desarrollo, el patrón de consumo $y$, en definitiva, el sistema de valores que nos inspira. Desde esta perspectiva es fácil comprender, como decíamos ya al comienzo de estas páginas, que la crisis económica y financiera actual tiene no poco que ver con este tema del desarrollo. Al menos, en dos sentidos: es una amenaza para que sigamos avanzando por la línea iniciada de una mayor atención a la cooperación; es un motivo que hace más urgente no abandonar esa senda emprendida.

En realidad la crisis revela de forma dramática lo que no es un problema nacido con ella: que las desigualdades a todos los niveles son un rasgo constitutivo de nuestro mundo. No cabe duda de que esta circunstancia añade inestabilidad e inseguridad, que se manifiesta de mil maneras, hasta llegar a convertirse en amenaza también para las sociedades en principio más avanzadas y más "seguras". Pero, sobre todo la existencia de desigualdades estructurales obliga a que nos preguntemos: $\dot{\partial}$ creemos realmente en la dignidad humana en que se fundamentan los derechos humanos, de los que con razón estamos tan orgullosos?, ¿̇aquellas desigualdades constitutivas no nos plantean con fuerza nuestras contradicciones?

Sobre las posibilidades para este mundo desigual ilustra el texto del ensayista José A. Marina:

Cuando se eliminan cinco grandes obstáculos -la miseria extrema, el miedo al poderoso, la ignorancia, el dogmatismo y el odio al vecino-todos los grupos sociales, con independencia de su religión o sus formas de vida, evolucionan hacia un marco ético que se caracteriza por el respeto a los derechos individuales, el rechazo de discriminaciones, la participación en el poder, la racionalidad como modo de resolver conflictos y las políticas de ayuda que implican una función social de la propiedad. El fundamento de este modelo es el reconocimiento de la dignidad de todos los seres humanos. La inteligencia compartida, la racionalidad social, nos lleva a esa meta ${ }^{50}$.

Las precedentes líneas, aunque no fuera ésa la intención de su autor, contextualizan bien el marco de la cooperación para el desarrollo. Las desigualdades son

50 J. A. MARINA (2007) Las arquitecturas del deseo. Una investigación sobre los placeres del espíritu, Barcelona, Anagrama, 185-186. 
de muchos tipos; la económica es uno de ellas, vinculada estrechamente con otros. La cooperación no puede moverse en el círculo estrecho de la transferencia de recursos, sino que tiene que actuar en el marco más amplio de los mecanismos que pretenden corregir estos dinamismos que generan o amplifican las desigualdades y las discriminaciones. Este marco más amplio es el que da sentido a la cooperación y le ofrece las coordenadas en que debe realizarse.

Las discriminaciones que se engendran y alimentan en un mundo como el nuestro nos llevan a recordar una convicción tanto más arraigada en la conciencia ética cuanto más ajena a ella vemos la realidad que nos circunda: el destino universal de los bienes de la tierra. Desde una perspectiva cristiana, este principio conecta con algo nuclear de la ética económica. Estamos ante un principio. El destino universal de los bienes, es previo y superior a otro, en el que sin embargo hasta mediados del siglo XX la doctrina social ha puesto más el acento: el derecho a la propiedad privada, consustancial al desarrollo de la sociedad occidental moderna. Incluso desde una ética puramente racional, parece que el destino universal de los bienes de la tierra es una consecuencia lógica del reconocimiento de la dignidad humana y deriva en un derecho universal. Desde este presupuesto, la propiedad privada no es sólo algo a defender y proteger, sino algo a promover.

La cooperación para el desarrollo, a renglón seguido, tiene que preguntarse: ¿qué desarrollo queremos promover ${ }^{21}$ Durante décadas el desarrollo se identificó demasiado precipitadamente con el crecimiento económico. ¿ंNo era la renta "per capita" el principal indicador empleado para medir el grado de desarrollo? Hoy entendemos el desarrollo de forma más completa, y también más compleja, gracias a la experiencia acumulada, a la reflexión interdisciplinar y a algunas aportaciones de relieve:

- Entre las propuestas que cuentan hoy con más apoyo hay que citar las de Amartya Sen, quien hizo una crítica aguda de los indicadores tradicionales y propuso luego centrar la atención en la ampliación de las capacidades de una persona para realizar las tareas que ella considera dignas de llevar a cabo en su vida. El hecho de que este enfoque esté ya muy difundido y asumido no es óbice para recordarlo aquí, pero nos ahorra detenernos más en él.

${ }^{51}$ Sobre esta cuestión ya reflexionamos en otro momento, cfr. CONSEJO DE REDACCIÓN (2005) "Desarrollo económico y social: teorías, propuestas y responsabilidades": Revista de Fomento Social 60 (2005) $11-38$. 
- El desarrollo humano ha de ser, además, inclusivo. Hoy podemos afirmar que el problema básico del desarrollo es, en términos éticos, un problema de equidad; en términos operativos, un problema de política de desarrollo y un problema de inclusión. En consecuencia, la inclusión debería estar en el núcleo de toda política y de las políticas de desarrollo (y no sólo el hambre y la pobreza, que son más bien los efectos).

Supuesto que tenemos claro qué tipo de desarrollo deseamos, hay que dar un paso más y preguntarse quiénes han de ser los actores de dichas políticas y cuáles son las responsabilidades de cada uno de ellos. Y no se puede negar que los principales responsables del desarrollo de los pueblos son los propios pueblos y sus gobiernos. No es superfluo afirmarlo para salir al paso de ciertos obstáculos muy relevantes. El primero de ellos es la corrupción de determinados gobiernos o, al menos, la falta de voluntad política para poner en marcha políticas eficaces; a veces ello no es más que el reflejo de administraciones públicas insuficientes o degradadas. La existencia de una violencia estructural en muchos de estos países, debida a causas endógenas (militarización de la política, incapacidad de las élites, conflictos por recursos naturales o de carácter identitario o tribal, etc.) hace que la ayuda externa sea irrelevante o contraproducente por cuanto favorece a los dictadores locales $\mathrm{u}$ otras formas de explotación local. Tampoco puede ignorarse la existencia de cierta psicología "victimista" con una base muy real, las estructuras injustas que mantienen a estos pueblos en su situación de retraso, pero con consecuencias menos justificables, como es cierto bloqueo para actuar, una pasividad y falta de reacción excesivas.

Las tareas que corresponden a los países en desarrollo son muchas y complejas, comenzando por esa ya aludida, que consiste en modernizar y fortalecer la capacidad del Estado y de la sociedad civil, es decir de gobernanza: para ello será imprescindible el establecimiento de una función pública profesional y efectiva, así como de un sistema fiscal justo y progresivo que dote a los poderes públicos de recursos suficientes y contribuya a la equidad.

Aunque no podamos enumerar todas las políticas a desarrollar, conviene insistir en que ese conjunto de políticas deberá estar debidamente articulado y jerarquizado. En este aspecto, merece una atención especial el desarrollo de los territorios rurales, porque es en éstos donde se encuentra el origen de muchas de las manifestaciones de la falta de desarrollo, hambre, pobreza, migración, tugurios urbanos, inseguridad, etc. Para hacer frente a esta compleja problemática es preciso depositar en manos de sus habitantes gran parte de la responsabilidad de su propio desarrollo y dotarles de los medios que les permitan ejercerla. Sólo así se logrará hacer más 
efectivas y sostenibles a largo plazo las políticas de servicios básicos y las sectoriales productivas. El desarrollo de los territorios rurales es todavía hoy el camino más efectivo para democratizar el desarrollo. Es triste la ceguera que muchos siguen mostrando ante esta evidencia, que se desprende de muchos años de experiencia en tareas de cooperación y desarrollo.

Dicho esto, hay que abordar en seguida la responsabilidad de los países desarrollados. Enumeramos a continuación algunos puntos sobre la misma:

$1^{\circ}$. Hemos de tomar conciencia que la creciente globalización de nuestras sociedades y de la economía intensifica los mecanismos generadores de desigualdades. Ésta es una ley permanente del mercado, que asigna bien los recursos a condición de que exista una cierta igualdad de partida entre los agentes que intervienen en él. Pero es evidente que en un mercado tan globalizado y que incluye a actores tan diversos, las desigualdades son también muy importantes. Plantear las acciones a emprender para controlar ese mercado globalizado y someterlo a ciertas regulaciones es algo previo a la cooperación, pues en caso contrario estaríamos ofreciendo con una mano lo que quitamos con la otra. Las iniciativas del gobierno español de reforzar nuestra cooperación deberían ir acompañadas de iniciativas equivalentes en esa otra línea. Y la reciente cumbre G-20 (noviembre 2008) puede ser un buen precedente aunque haya estado motivada por problemas que afectan a los países desarrollados más que a los subdesarrollados: en todo caso, es un paso adelante significativo en la búsqueda de mecanismos que lleven a cierta regulación de los mercados (de momento, los financieros).

$2^{\circ}$. Todo mercado-mucho más el mercado global- necesita establecer mecanismos correctores de las desigualdades que espontáneamente genera. Porque, por muy bien que funcione un mercado, nunca lo hará en las condiciones ideales que garantizarían una asignación equitativa de los recursos. La cooperación al desarrollo es una forma, no la única, de actuar en ese sentido corrector. Ella supone una transferencia de recursos para recomponer equilibrios deshechos desde hace siglos entre los países ricos y los pobres.

$3^{\circ}$. Desde el punto de vista de la justicia habría que invocar aquí el principio clásico de la restitución. Fue formulado para regular relaciones interindividuales y exige que, cuando alguien se apropia indebidamente de lo que no es suyo, lo devuelva a su legítimo dueño. Pero puede ser traducido a las relaciones entre los pueblos: si en este caso no parece fácil determinar las cantidades exactas que habría que restituir, eso no invalida el principio mismo, sino que refuerza 
y legitima la transferencia de recursos hacia pueblos que han sido expoliados durante siglos.

$4^{\circ}$. Si admitimos las leyes de la economía para las que un móvil determinante es la obtención de un beneficio, no podemos dejar de plantearnos qué ventajas trae a los donantes su acción. Es cierto que hay donaciones desinteresadas, pero hay que contar desde un elemental realismo que no siempre lo sean. Un caso típico es el de los créditos FAD, al que ya nos hemos referido. Habría que aplicar aquí lo que vale para toda la actividad económica. La obtención de un beneficio no puede perjudicar al objetivo final de la actividad que siempre habrá de ser un bien para la sociedad: el beneficio es, en último término, la retribución que hace la sociedad de un servicio que el agente económico le presta. No es inmoral buscarlo, pero puede serlo por la forma en que se busca, y lo será siempre que la obtención del mismo redunde en algo que es malo para la sociedad. Traducido a la cooperación: que las actividades que en ella se engloban no se enfoquen de tal manera que produzcan perjuicios en vez de beneficios a los destinatarios, aunque esto no se llegue a percibir a corto plazo.

$5^{\circ}$. Orientar la cooperación según un adecuado concepto del desarrollo es esencial para evitar que aquélla se convierta en otra forma de mantener la dependencia de los destinatarios respecto a los donantes, más civilizada, pero igualmente contraria al verdadero desarrollo de los pueblos. Es fundamental aquí que el desarrollo se oriente a potenciar las personas, en facilitar su progresivo protagonismo, en "empoderarlas". Así lo subraya Benedicto XVI en su reciente Mensaje para la Jornada mundial de la Paz:

Por otro lado, es innegable que las políticas marcadamente asistencialistas están en el origen de muchos fracasos en la ayuda a los países pobres. Parece que, actualmente, el verdadero proyecto a medio y largo plazo sea el invertir en la formación de las personas $y$ en desarrollar de manera integrada una cultura de la iniciativa ${ }^{52}$.

En resumen, se trata de movilizar a todas las sociedades desde una acción coordinada, en cada país pero también del conjunto de países. Lo económico es determinante. Pero exige una voluntad política adecuadamente canalizada. Y exige, sobre todo, del apoyo y la iniciativa de la sociedad civil, la de los pueblos menos desarrollados, pero también la de quienes vivimos en sociedades de

52 Benedicto XVI (2008) Combatir la pobreza, construir la paz. Mensaje para la celebración de la Jornada mundial de la Paz, 1 de enero de 2009, 11. Cfr. el texto en este número, pp. 131-140. 
abundancia y de confort, a quienes esos problemas nos llegan como un rumor lejano y casi imperceptible. Así lo sintetizaba también el citado mensaje:

Finalmente, situar a los pobres en el primer puesto comporta que se les dé un espacio adecuado para una correcta lógica económica por parte de los agentes del mercado internacional, una correcta lógica política por parte de los responsables institucionales y una correcta lógica participativa capaz de valorizar la sociedad civil local e internacional $^{53}$.

Y, en palabras de la ya también citada nota de la Santa Sede sobre financiación del desarrollo:

La experiencia de cooperación internacional al desarrollo es hoy suficientemente amplia para permitir concluir que las políticas y los recursos "llegados de lo alto" pueden producir efectos benéficos inmediatos, pero por sí solos no proporcionan respuestas adecuadas a cómo salir, de forma sostenible, de la pobreza. Los principios de subsidiariedad y solidaridad, tan queridos a la doctrina social de la lglesia, pueden inspirar un auténtico desarrollo en el signo de un humanismo integral y solidario ${ }^{54}$.

La versión inglesa del editorial está disponible en la página de la revista

\section{www.revistadefomentosocial.es}

Tanto el texto en castellano como la versión en inglés son accesibles desde la aparición del número.

${ }^{53} \mathrm{lbid} ., 12$.

${ }^{54}$ Nota de la Santa Sede Financiación y desarrollo, sobre la financiación del desarrollo en vísperas de la Conferencia de Doha, 18-XI-2008, 8. 